\title{
Onset of Puberty in Relation to Obesity
}

\author{
JEESON C UNNI \\ Consultant Pediatrician, Dr Kunhalus Nursing Home, TD Road, Kochi, Kerala, India. \\ jeeson@asianetindia.com
}

T he process of pubertal development and the factors affecting it are only partly understood even today. Owing to the rising epidemic of childhood obesity, there have been a number of studies investigating the role of body composition, and the rate and timing of puberty. There is evidence now that increased height and body mass index (BMI) of children, prior to puberty, result in an earlier onset of puberty $[1,2]$.

Rapid weight gain in early life has been linked to advanced puberty in both sexes, more so amongst girls [3]. Early onset of thelarche has been reported in girls with high BMI at the age of three years, and in those with a rapid elevation of BMI from three years of age to the age of entry into the first grade [4]. The rapid catch-up growth in children born small-for-gestational age [5] with associated decreased insulin sensitivity, and increased IGF-1 levels, also results in early onset of pubarche for the same reason.

A definite association exists between increasing BMI and earlier pubertal development in girls, and the study [6] published in this issue of Indian Pediatrics also confirms this association. Majority of studies suggest early puberty and voice cracking in obese boys, but some studies have contradictory results. Till recently, little was known regarding genes regulating puberty. Studies have now identified gene loci [myocardin-like 2 (MKL2) for male sexual development, menarche locus linking earlier puberty with reduced pubertal growth, and loci for short stature in boys and girls] that may explain the factors influencing obesity and pubertal changes [7]. BMIincreasing alleles in girls correlated well with earlier breast development but in boys they are associated with early sexual development in some and delayed sexual development in others. This could explain the conflicting results of studies analyzing pre-pubertal obesity and onset of puberty in boys. Though the mechanisms regulating pubertal onset in males and females may be similar to a large extent, the relationship in boys may be complex requiring further genetic studies.
Adiposity has been proposed as a metabolic gatekeeper of central pubertal initiation but the postulation that central activation of $\mathrm{GnRH}$-gonadotropin axis in obese girls may be the cause for premature thelarche has not been proven. The peripheral aromatization of the vast adipose tissue androgens to estrogens [8], the insulin-induced reductions of sex hormone binding globulin (SHBG) which increases bioavailability of sex steroids including estradiol [9], and the hyperinsulinemia in obese girls contribute to early onset of thelarche. However, the time from thelarche to menarche may be delayed in obese girls suggesting that the increase in estrogen in obesity may not be gonadotropin-dependent [10], and the isolated menstrual bleeds may represent nonovulatory bleeding.

Obesity increases pubertal insulin resistance, especially in girls [11]. This and the resultant hyperinsulinemia may advance pubertal maturation in these children. The fact that African-American children, who are genetically prone to insulin resistance, attain pubertal milestones earlier than their peers [12], highlights the affect of insulin resistance on puberty.

As mentioned earlier, we are still in the dark regarding various aspects of the influence of obesity on pubertal development. Several questions remain unanswered. More research is needed to clearly delineate the effects of excess adiposity on pubertal development in boys. Whether gonadotropin-dependent or independent mechanisms underlie early thelarche in obese girls remains to be established. Also implications of hyperandrogenemia during early puberty and their role in advancing puberty need to be studied.

Developing screening tools and strategies for preventive and curative management of obesity-related reproductive problems in adolescents will need a clearer understanding of the complex etiopathogenesis of the condition in both sexes.

Funding: None; Competing interest: None stated.

\section{REFERENCES}

1. Cooper C, Kuh D, Egger P, Wadsworth M, Barker D. 
Childhood growth and age at menarche. $\mathrm{Br} \mathrm{J}$ Obstet Gynaecol. 1996;103:814-7.

2. He Q, Karlberg J. BMI in childhood and its association with height gain, timing of puberty, and final height. Pediatr Res. 2001;49:244-51.

3. Papadimitriou A, Nicolaidou P, Fretzayas A, Chrousos GP. Clinical review: Constitutional advancement of growth, a.k.a. early growth acceleration, predicts early puberty and childhood obesity. J Clin Endocrinol Metab. 2010;95:4535-41.

4. Lee JM, Appugliese D, Kaciroti N, Corwyn RF, Bradley $\mathrm{RH}$, Lumeng JC. Weight status in young girls and the onset of puberty. Pediatrics. 2007;119:e624-30.

5. Verkauskiene R, Petraitiene I, Albertsson Wikland K. Puberty in children born small for gestational age. Horm Res Paediatr. 2013;80:69-77.

6. Khadgawat R, Marwaha RK, Mehan N, Surana V, Dabas A, Sreenivas V, et al. Age of onset of puberty in apparently healthy school girls from Northern India. Indian Pediatr. 2016;53:383-7.
7. Cousminer DL, Stergiakouli E, Berry DJ, Ang W, GroenBlokhuis MM, Körner A, et al.; Early Growth Genetics Consortium. Genome-wide association study of sexual maturation in males and females highlights a role for body mass and menarche loci in male puberty. Hum Mol Genet. 2014;23:4452-64.

8. Dunger DB, Ahmed ML, Ong KK. Effects of obesity on growth and puberty. Best Pract Res Clin Endocrinol Metab. 2005;19:375-90.

9. Ahmed ML, Ong KK, Dunger DB. Childhood obesity and the timing of puberty. Trends Endocrinol Metab. 2009; 20:237-42.

10. Jasik CB, Lustig RH. Adolescent obesity and puberty: the "perfect storm." Ann N Y Acad Sci. 2008;1135: 265-79.

11. Pilia S, Casini MR, Foschini ML, Minerba L, Musiu MC, Marras V, et al. The effect of puberty on insulin resistance in obese children. J Endocrinol Invest. 2009;32:401-5.

12. Hoffman RP. Metabolic syndrome racial differences in adolescents. Curr Diabetes Rev. 2009;5:259-65. 